\title{
Acute Liver Failure Complicating Viral Hepatitis A
}

\author{
Daniel Rui Diniz-Santos, Maria Clotildes Nunes de Melo, \\ Rita Franca Melo and Luciana Rodrigues Silva
}

\author{
Pediatric Gastroenterology and Hepatology Division, \\ Professor Hosannah Oliveira Pediatric Centre, \\ Federal University of Bahia, Salvador, BA, Brazil
}

\begin{abstract}
Hepatitis A is one of the most frequent infectious liver diseases affecting children worldwide. The disease is usually mild and self-limited, and complications are very rare. Nevertheless, hepatitis A can sometimes cause acute liver failure (ALF), a severe, life-threatening condition. Herein is reported a case of a child who presented ALF during a course of hepatitis A. The need for early identification of possible ALF cases among hepatitis A patients, and for effective ways of evaluating such a possibility, are discussed. We also emphasize the importance of prevention measures, especially vaccination.

Key Words: Hepatitis A, acute liver failure, children.
\end{abstract}

Among the infectious liverdiseases, viral hepatitis A is one of the most frequent in the pediatric population. The clinical picture of viral hepatitis A is extremely variable, ranging from asymptomatic infection to fulminant disease. In the majority of the symptomatic cases, hepatitis A presents as a mild, self-limited disease, whose cardinal manifestations include a prodrome of anorexia, malaise, nausea, vomiting, low-grade fever $\left(38^{\circ} \mathrm{C}-39^{\circ} \mathrm{C}\right)$, myalgia, arthralgia and non-specific flu-like symptoms affecting the upper respiratory tract. Prodromic symptoms may last for up to two weeks, and they usually vanish as jaundice becomes clinically apparent. Choluria and fecal hypocholia may be observed one to five days before the onset of jaundice. Right-upper quadrant abdominal pain is also a common feature. Extra-hepatic manifestations are rare and total cure is expected to occur spontaneously within six months; only symptomatic treatment is required during that period.

Acute liver failure (ALF) is defined by the onset of jaundice, coagulopathy and encephalopathy within

Received on 12 August 2003; revised 19 December 2003.

Address for correspondence: Dr. Luciana Rodrigues Silva. Rua Ceará, 360, apto. 701, Pituba, Salvador, Bahia, Brazil. Zip code: 41830-451. Phone: (55 71) 353-3069.

E-mail: lupe.ssa@uol.com.br

The Brazilian Journal of Infectious Diseases 2004;8(2):180-183 (C) 2004 by The Brazilian Journal of Infectious Diseases and Contexto Publishing. All rights reserved. eight weeks, in the absence of prior liver disease [1]. There are several causes of ALF: metabolic diseases, vascular abnormalities, drug-induced pictures (acetaminophen, Amanita) and viral hepatitis, which account for the majority of pediatric ALF cases in many areas of the world. Viral hepatitis A is one of the most important causes of ALF in children, besides hepatitis B, D and E, Epstein-Barr virus, cytomegalovirus, parvovirus and acetaminophen overdoses. Even though there is evidence of specific genetic features in viruses found in ALF patients [2], the reason why some hepatitis A patients present ALF, whereas most of them present a self-limited picture, remains known.

In ALF, massive hepatocellular necrosis takes place, accounting not only for jaundice, coagulopathy and encephalopathy, butalso for suggestive laboratory findings, such as markedly high alanine aminotransferase (ALT) blood levels, in contrast to elevations of aspartate aminotransferase (AST) blood levels found under less severe conditions, in which necrosis is not so massive. The majority of processes eliciting ALFare transient, which means only supportive treatment is needed if the patient is able to survive long enough for the liver to recover its function. Adequate management should be done in an intensive care unit, paying special attention to the appearance of potentially deadly complications, like cerebral edema, digestive bleeding, renal failure and sepsis. 
Acute liver failure is an extremely uncommon complication of viral hepatitis A, occurring in $0.1 \%-0.4 \%$ of the pediatric cases [3]. Nevertheless, older patients, chiefly those older than 40 years old, are more likely not only to present ALF, but also to suffer from symptomatic hepatitis A. In spite of the development of new techniques, ALF mortality rate is above $80 \%$ and the only curative treatment is liver transplantation, which reinforces the importance of preventive measures.

\section{Case Report}

A two-year old girl was admitted to the Pediatric Gastroenterology and Hepatology Division, Professor Hosannah Oliveira Pediatric Centre, Federal University of Bahia, presenting low-grade fever, malaise, choluria and hypocholia for five days. The patient was jaundiced $(+++/ 4)$ and the abdomen was distended, diffusely tender and both hepatomegaly and splenomegaly were detected. The vital signs were: blood pressure $=120 \times 70$ $\mathrm{mm} \mathrm{Hg}$, heart rate $=160 \mathrm{bpm}$, respiratory rate $=45$ ipm (Kussmaul breathing). Relevant laboratory findings are presented in Table 1.

Markedly decreased prothrombin time associated with high levels of blood bilirubin were enough to determine the diagnosis of ALF, despite the lack of evidence of encephalopathy, which can be impossible to assess in early childhood. Detection of anti-HVA IgM antibodies evidenced the etiology of the process.

The usual treatment for ALF was initiated, including oxygen support, mannitol, dobutamine, fluid and electrolyte management and correction of acid-base balance. The patient responded well, correcting prothrombin time, presenting reduced aminotransferase blood levels (as shown in Figure 1) and recovery of all other hepatocellular disfunction and cholestasis indicators. The patient was dismissed after 13 days.

\section{Discussion}

A case of ALF complicating the evolution of viral hepatitis A is presented. Even though children are the main victims of hepatitis A in endemic areas, ALF is an infrequent complication among children, since the possibility of fulminant evolution rises with age, peaking above the age of 40 years [3].

Although viral hepatitis A is usually a mild, self-limited disease, high mortality rates for ALF in children and adolescents stress the need of early identification of patients who present severe evolution. Aiming at that identification, several prognostic criteria adopted in the management of patients with a poor evolution have been discussed [4-6], often assessing liver functional ability. In pediatric cases, the criteria most often adopted are a sudden fall in prothrombin time, a strongly progressive elevation in total blood bilirubin and a quick, sudden reduction of hepatometry. The prognostic criteria used to evaluate hepatic encephalopathy are quite difficult to assess in early childhood. In these cases, suspicion can be based on disturbance of sleeping patterns, lack of interest in the surroundings, and irritability.

Thus, viral hepatitis A is a typically mild, self-limited disease, which may, at a given moment in its clinical evolution, be deadly. The pediatric population is more vulnerable, especially those children living in poor economic conditions, who are more likely to become sick and to present complications. Considering the availability of safe and effective vaccines [7], cases of ALF due to viral hepatitis A should not occur any longer. In spite of such availability, in many parts of the world viral hepatitis $A$ is still the major cause of acute liver failure in children.

The vaccination guidelines against hepatitis A virus must be reviewed and expanded, favoring general immune prophylaxis in order to prevent the occurrence of ALF and other severe complications, such as autoimmune hepatitis, cholecystitis, acute renal failure and autoimmune thrombocytopenic purpura. However, the most important measure to be taken is the improvement of sanitary conditions, which would definitely break the viral cycle.

Improvements of hygiene conditions over the last few decades have resulted in a significant reduction in the prevalence of hepatitis A infection, thus creating a growing population of seronegative unprotected adults, which are more likely to suffer from symptomatic viral 
Table 1. Laboratorial findings at first day of hospitalization

\begin{tabular}{ll}
\hline Total bilirrubin & $10.6 \mathrm{mg} / \mathrm{dL}$ \\
Conjugated bilirrubin & $8.4 \mathrm{mg} / \mathrm{dL}$ \\
AST & $1,484 \mathrm{U} / \mathrm{I}$ \\
ALT & $885 \mathrm{U} / \mathrm{I}$ \\
Alcaline phosphatasis & $581 \mathrm{U} / \mathrm{I}$ \\
$\gamma$-glutamil transferase & $387 \mathrm{U} / \mathrm{I}$ \\
Amilase & $30 \mathrm{U} / \mathrm{I}$ \\
Total white cells count & $10,400 / \mathrm{mm} 3$ \\
& $(\mathrm{~S} 52 \mathrm{~B} 14 \mathrm{~L} 19 \mathrm{M} 3 \mathrm{E} 0)$ \\
Protombine time & $23 \%$ \\
Total blood proteins & $4.9 \mathrm{~g} / \mathrm{dL}$ \\
Albumin & $1.9 \mathrm{~g} / \mathrm{dL}$ \\
Globulin & $3.0 \mathrm{~g} / \mathrm{dL}$ \\
Anti-HVA IgM & Positive \\
Anti-HCV IgM & Negative \\
Anti-HBC IgM & Negative \\
AgHBs & Negative \\
\hline
\end{tabular}

Figure 1. Aminitransferases daily blood levels during hospitalization

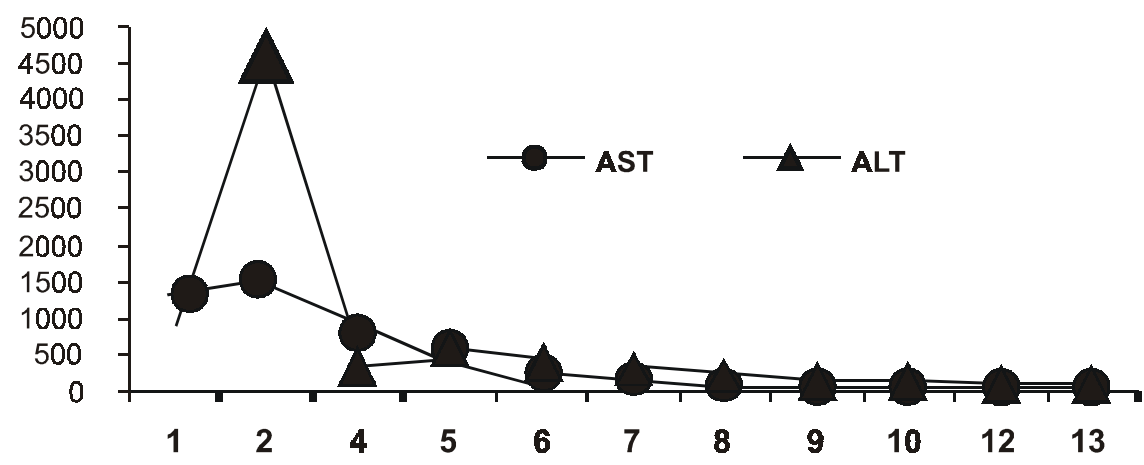

hepatitis A and its complications. A cost-benefit analysis concluded that the adoption of a nationwide infant vaccination program is not only medically but also economically justifiable [8]. This vaccine has already been included in the regular immunization schedule in several countries. Unfortunately, this has not occurred in Brazil yet.
We stress the importance of a high level of suspicion of ALF in the management of an atypical clinical and laboratory picture, and in patients who, during the course of viral hepatitis A, develop any disturbance in sleeping pattern or present signs of encephalopathy or coagulopathy, fluid and electrolyte imbalance and sudden reduction of hepatometry. Another important 
aspect is the need for governmental initiatives in order to vaccine every child between one and two years of age against viral hepatitis $\mathrm{A}$.

\section{References}

1. Trey C., Davidson C.S. Management of fulminant hepatic failure. In: Popper H., Schaffner F., eds. Progress in liver disease. Vol. III. New York: Grune \& Stratton, 1970:282-98

2. Fujiwara K., Yokosuka O., Fukai K., et al. Analysis of fulllength hepatitis A virus genome in sera from patients with fulminant and self-limited acute type A hepatitis. J Hepatol 2001 Jul;35(1):112-9

3. Whitington P.F., Soriano H.E., Alonso E.M. Fulminant Hepatic Failure in Children. In: Suchy F.J., Sokol R.J., Balistreri W.F., eds. Liver Disease in Children. Lippincott Williams \& Wilkins 2001:63-88

4. O’Grady J.G., Alexander G.J.M., Hayllar K.M., Willaiams R. Early indicators of prognosis in fulminant hepatic failure. Gastroenterology 1989;97:439.

5. Bernuau J., Goudeau A., Poynard T., et al. Multivariate analysis of prognostic factors in fulminant hepatitis B. Hepatology 1986;6:648.

6. Dhiman R.K., Seth A.K., Jain S., et al. Prognostic evaluation of early indicators in fulminant hepatic failure by multivariate analysis. Dig Dis Sci 1998 Jun;43(6):1311-6.

7. Eng R.S.M., Pomerantz R.J., Friedman L.S. Hepatitis A vaccines: past, present and future. Gastroenterology 1993;105(3):943-6.

8. Gimberg G.M., Slater P.E., Shouval D. Cost-benefit analysis of a nationwide infant immunization programme against hepatitis A in an area of intermediate endemicity. J Hepatol 2001;34:92-9 